\title{
DNA extraction protocol for low-biomass environmental samples: adapted from the Lucigen MasterPure Complete DNA and RNA Purification Kit manual
}

Jiaxian Shen

Northwestern University https://orcid.org/0000-0003-4929-8955

Erica M. Hartmann ( $\nabla$ erica.hartmann@northwestern.edu )

Northwestern University

\section{Method Article}

Keywords: DNA extraction, low-biomass, environmental, liquid-liquid extraction

Posted Date: February 10th, 2022

DOl: https://doi.org/10.21203/rs.3.pex-1658/v1

License: (c) (1) This work is licensed under a Creative Commons Attribution 4.0 International License. Read Full License 


\section{Abstract}

Microbial samples collected from built environment surfaces can be very low-biomass. This poses a critical challenge to extract valid signals out of the background noises for downstream analyses. Upon comparing and optimizing several extraction methods, our results demonstrated that bead-beating and heat lysis followed by liquid-liquid extraction was the optimal method, as opposed to widely used column- and magnetic bead-based methods. Adapted from the Lucigen MasterPure Complete DNA and RNA Purification Kit manual, this protocol demonstrates detailed points that merit special attention for low-biomass environmental samples.

\section{Introduction}

\section{Reagents}

\section{Material}

o Ice

o $1.5 \mathrm{~mL}$ sterile microcentrifuge tube (No. $=2 \times$ sample No.)

o $O$ ring tube (Cat\# 10831; BIOSPEC PRODUCTS INC)

o 0.1 MM ZIRCONIA/SILICA BEADS (Cat\# 11079101Z; BIOSPEC PRODUCTS INC)

$0.2 \mathrm{~mL}$ beads for $0.5 \mathrm{~mL}$ liquid

Fill with $0.2 \mathrm{~mL}$ autoclaved PCR tubes

Use sterile forceps to handle

Fill in biosafety cabinet

\section{Reagent}

o Isopropanol

o Lucigen MasterPure Complete DNA and RNA Purification Kit (Cat\# MC85200; Lucigen Biosearch Technologies)

o Invitrogen ${ }^{\text {TM }}$ Nuclease-Free Water (not DEPC-Treated) (Cat\# AM9937) 


\section{Volume of sample each tube}

○ $250 \mu \mathrm{L}$

\section{Equipment}

1. Eppendorf ThermoMixer

2. Eppendorf centrifuge 5424

3. Mini-Beadbeater-96 (Cat\# 1001, BioSpec Products)

4. Fisherbrand ${ }^{\text {TM }}$ Analog Vortex Mixer (Cat\# 02-215-414)

5. Eppendorf concentrator plus/vacufuge plus

\section{Procedure}

\section{Do in advance}

1. Thaw samples

2. Get ice

3. Set thermomixer to be $65^{\circ} \mathrm{C}$

4. Set centrifuge to be $4^{\circ} \mathrm{C}$

\section{Lysis of samples}

Thoroughly mix the various Lysis Solutions to ensure uniform composition before dispensing.

1. Dilute $1.666 \mu \mathrm{L}$ of Proteinase K into $250 \mu \mathrm{L}$ of $2 X \mathrm{X}$ and C Lysis Solution for each sample.

2. Transfer $250 \mu \mathrm{L}$ of the fluid sample to an 0 ring tube (prefilled with beads), add $250 \mu \mathrm{L}$ of $2 X \mathrm{~T}$ and $\mathrm{C}$ Lysis Solution containing the Proteinase $\mathrm{K}$, and mix thoroughly using vortex.

3. Bead-beating lysis for 5 min (no more than 12 tubes each time). 
4. Incubate at $65^{\circ} \mathrm{C}$ for 25 minutes in ThermoMixer; vortex every 5 minutes; set the shaking speed at 300 rpm during the incubation.

5. Centrifuge the tubes at $12,000 \times \mathrm{g}$ for $3 \mathrm{~min}$ at room temperature.

6. Transfer $350+10 \mu \mathrm{L}$ supernatant to a new microcentrifuge tube.

- Use different pipettes $(1000 \mu \mathrm{L}+20 \mu \mathrm{L})$ to recover the maximum possible volume.

- This volume was determined upon testing. This could be adjusted according to sample characteristics.

- Recommend documenting this volume for future trace-back.

7. Cool the samples to $37^{\circ} \mathrm{C}$ (just change the temperature of the ThermoMixier to $37^{\circ} \mathrm{C}$ and wait until $37^{\circ} \mathrm{C}$ is reached) and add $1.666 \mu \mathrm{L}$ of $5 \mathrm{mg} / \mathrm{mL}$ RNase A to the sample. Mix thoroughly.

8. Incubate at $37^{\circ} \mathrm{C}$ for 50 minutes, still shaking at $300 \mathrm{rpm}$.

9. Place the samples on ice for 5-8 minutes and then proceed with total DNA precipitation.

\section{Total DNA precipitation}

10. Add $330 \mu \mathrm{L}$ of MPC Protein Precipitation Reagent to lysed sample and vortex vigorously for 10 seconds.

11. Pellet the debris by centrifugation at $4^{\circ} \mathrm{C}$ for 18 minutes at $16,000 \mathrm{xg}$ in a microcentrifuge.

- If the resultant pellet is clear, small, or loose, add an additional $25 \mu \mathrm{L}$ of MPC Protein Precipitation Reagent, mix, and pellet the debris again.

- This protocol has already added $80 \mu \mathrm{L}$ more MPC reagent compared to the kit manual.

12. Transfer the supernatant to a clean microcentrifuge tube and discard the pellet. Use different pipettes $(1000 \mu \mathrm{L}+20 \mu \mathrm{L})$ to slowly and gently suction the maximum possible volume while maintaining the pellet intact.

- Followed by $1000 \mu \mathrm{L}$ pipette, $20 \mu \mathrm{L}$ pipette is used because the pellet is easy to be dislodged by the disturbance from the strong suction force of $1000 \mu \mathrm{L}$ pipette. By using pipettes with a smaller volume, we can recover more liquid while avoiding contaminants in the pellet.

- In theory, expect $\sim 670 \mu \mathrm{L}$ of the supernatant, but in practice, I only recovered $600+20 \mu \mathrm{L}$ supernatant. This volume could be adjusted according to sample characteristics. Recommend documenting this volume for future trace-back. 
13. Add $834 \mu \mathrm{L}$ of isopropanol to the recovered supernatant. Invert the tube 50-60 times.

14. Pellet the DNA by centrifugation $(16,000 \times \mathrm{g})$ at $4^{\circ} \mathrm{C}$ for 18 minutes in a microcentrifuge.

15. Carefully remove the isopropanol without dislodging the DNA pellet, using a pipette.

16. Rinse twice with fresh $70 \%$ ethanol, being careful not to dislodge the pellet. Centrifuge briefly in between each washing step ( $2 \mathrm{~min} ; 16,000 \mathrm{xg}$ ). Remove all of the residual ethanol with a pipette.

17. Vacuum centrifuge the sample at room temperature for 2 min under V-AQ mode. The indicator is that the DNA pellet turns from white to transparent.

- This time could be adjusted. Try adding 1 min (or even $30 \mathrm{~s}$ ) each time at the beginning of working with a new sample to avoid over-drying.

- For reference, I vacuum centrifuged 2 min +1 min for my samples.

18. Resuspend the DNA in $50 \mu \mathrm{L}$ of DNase-free water. Disrupt the DNA pellet gently by gently flicking the tube. If necessary, leave the DNA at $4{ }^{\circ} \mathrm{C}$ overnight to rehydrate.

\section{Troubleshooting}

\section{Time Taken}

\section{Anticipated Results}

\section{References}

1. Lucigen MasterPure ${ }^{\mathrm{TM}}$ Complete DNA and RNA Purification Kit manual: MA110E-MasterPure-Complete

2. Blaustein, R. A., Michelitsch, L. M., Glawe, A. J., Lee, H., Huttelmaier, S., Hellgeth, N., . . Hartmann, E. M. (2021). Toothbrush microbiomes feature a meeting ground for human oral and environmental microbiota. Microbiome, 9(1), 32. doi:10.1186/s40168-020-00983-x. 